\title{
Toward Compact Monotonically Compositional Interlingua Using Lexical Aspect
}

\author{
Bonnie J. Dorr, Mari Broman Olsen, and Scott C. Thomas \\ Institute for Advanced Computer Studies \\ University of Maryland \\ College Park, MD, USA 20742 \\ \{bonnie,molsen, scthmas\}@umiacs. umd.edu
}

\begin{abstract}
We describe a theoretical investigation into the semantic space described by our interlingua (IL), which currently has 191 main verb classes divided into 434 subclasses, represented by 237 distinct Lexical Conceptual Structures (LCSs). Using the model of aspect in Olsen (1994; 1997) - monotonic aspectual composition-we have identified 71 aspectually basic subclasses that are associated with one or more of 68 aspectually non-basic classes via some lexical ("type-shifting") rule (Bresnan, 1982; Pinker, 1984; Levin and Rappaport Hovav, 1995). This allows us to refine the IL and address certain computational and theoretical issues at the same time. (1) From a linguistic viewpoint, the expected benefits include a refinement of the aspectual model in (Olsen, 1994; Olsen, 1997) (which provides necessary but not sufficient conditions for aspectual composition), and a refinement of the verb classifications in (Levin, 1993); we also expect our approach to eventually produce a systematic definition (in terms of LCSs and compositional operations) of the precise meaning components responsible for Levin's classification. (2) Computationally, the lexicon is made more compact.
\end{abstract}

\section{Introduction}

In this paper we describe a theoretical investigation into the semantic space described by our interlingua (IL). We wish to restrict our lexicon to the most basic lexical structures (as described below), deriving the rest by a small set of lexical rules. To do this, we make direct use of the model of aspect in Olsen (1994; 1997), further described in Section 3, in order to find the pairs of verb classes that are compositionally related by aspect (Section 4). The aspectual relation, in turn, points us in the direction of a systematic account of the components of meaning that determine the classification of verbs in (Levin, 1993). Determining the most effective lexical representations and rules for defining the verb lexicon

comprise the next step of this investigation (Section 5). First we describe our interlingual representation and its role in the handling of lexical variation, both within a language and across languages. 


\section{Interlingual Lexical Conceptual Structures}

Our approach to machine translation (MT) employs lexical conceptual structures (LCSs) (Dorr et al., 1993; Dowty, 1979; Guerssel et al., 1985)—an augmented form of (Jackendoff, 1983; Jackendoff, 1990) - as the basis of an interlingua. An LCS is designed to be a language-independent, compositional representation, making use of primitives (GO, BE, STAY, etc.), types (Event, State, Path, etc.), and fields (Loc(ational), Temp(oral), Poss(essional), Ident(ificational), Perc(eptual), etc.). There are currently 434 subclasses of verbs, represented by 237 distinct LCSs in our lexicon. LCSs serve as an interlingua in two applications: machine translation (Dorr et al., 1993) and foreign language tutoring (Dorr et al., 1995; Sams, 1993; Weinberg et al., 1995).

The use of LCS as an interlingua-refined in accordance with aspectual considerations (as described below) - enables us to provide a systematic treatment of cases where the composition of basic lexical structures with tempo$\mathrm{ral} /$ aspectual components accommodates both within-language and cross-language variation.

Consider the following English sentences:

(1) (i) John vacationed at home.

(ii) John spent his vacation at home.

(iii) John stayed at home during his vacation.

Each of these three sentences corresponds to the following LCS:

(2) (stay loc (john) (at loc (john) (home))

(for temp (*head*) (vacation)))

For (1)(i), the LCS is derived directly from the lexical entry for vacation, whereas for (1)(ii) and (iii), the LCS is derived compositionally from the following two sub-components:

(3) (i) (stay loc (john) (at loc (john) (home)))

(ii) (for temp (*head*) (vacation))

Since there is no equivalent Spanish verb for the English verb vacation, the LCS in (2) corresponds to sentences such as John se pasó las vacaciones en casa ('John spent his vacation at home') or John se quedó en casa durante las vacaciones ('John stayed at home during vacation'), i.e., the Spanish case would be derived compositionally, in the same way that the first two English sentences above are dervied. While other approaches (e.g., (Nirenburg et al., 1992)) provide mechanisms for handling such cases, the approach described here differs in that it supports a systematic association-monotonic composition-of basic templates to their composed counterparts, requiring only the existence of a small set of lexical rules. ${ }^{1}$ The next section describes the relation between LCS and lexical aspect.

\footnotetext{
${ }^{1}$ It should also be noted that using the LCS-based approach supports large-scale acquisition
} 


\begin{tabular}{|l|l|l|l|l|}
\hline Aspectual Class & Telic & Dynamic & Durative & Examples \\
\hline State & & & + & know, have \\
\hline Activity & & + & + & march, paint \\
\hline Accomplishment & + & + & + & destroy \\
\hline Achievement & + & + & & notice, win \\
\hline
\end{tabular}

Table 1: Privative Featural Identification of Aspectual Classes

\section{Lexical Aspect}

Following Olsen (1997), we use lexical aspect to refer to the situation type denoted by the verb alone, or combined with other sentential constituents. Verbs are assigned to lexical aspect classes, as in Table 1, based on their behavior in a variety of syntactic and semantic frames that focus on these features. (Olsen, 1997, pp. 32-33).

As a number of researchers have pointed out (Dowty, 1979; Moens and Steedman, 1988; Olsen, 1994; Pustejovsky, 1991; Smith, 1991; Verkuyl, 1972; Verkuyl, 1993), verbs appear to have multiple aspectual types, depending on (and seemingly "coerced" by) the presence of other sentential constituents, such as those introduced by the alternations cataloged by Levin (1993). Olsen constrains this "type-shifting" by allowing only monotonic composition of privative lexical aspect features $(+/ \emptyset$ instead of $+/-/ \emptyset)$; features are added but not deleted. For instance, a state may become an activity (by adding [+dynamic]), and an activity may become an accomplishment (by adding [+telic]).

Dorr and Olsen (1997) investigate the relationship between the lexical aspect of verbs, alone and in sentential contexts, and LCSs whose construction is guided by the alternations in Levin (1993). A simple example of the relationship is shown by the Fill Verbs (Class 9.8 (Levin, 1993)), which appear in the atelic state LCS in (4), as well as the telic event LCS in (5). ${ }^{2}$

(4) Tinsel covered the tree.

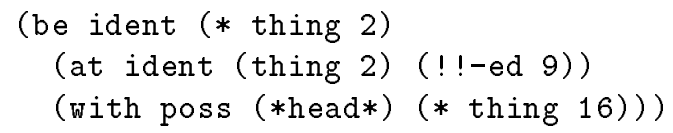

(5) I covered the tree with tinsel.

of lexicons for multiple languages for NLP applications; see, e.g., (Dorr, 1997; Dorr, To appear).

${ }^{2}$ The numbers in the LCSs stand for theta-roles: 1 = agent, 2 = theme, etc. '!!' stands in for the actual verb (the 'constant'), e.g., the token filled for the verb fill. 


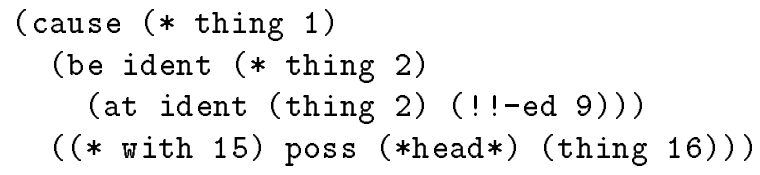

In this case the compositionality implicit in Levin's listed alternations (1993) is readily handled by Jackendoff (1983)-style LCSs: these templates are clearly related by subsumption, with (4) embedded in (5). It also mirrors the aspect structure found in Dorr and Olsen (1997): this instance of causativization coincides with a change in aspect.

For many verb classes, however, it is possible to come up with several different, equally plausible LCSs, focusing on different aspects of the class semantics. Consider the following LCSs, representing two uses of the Manner Subclass of Wipe Verbs (Class 10.4.1):

(6) I buffed the floor.

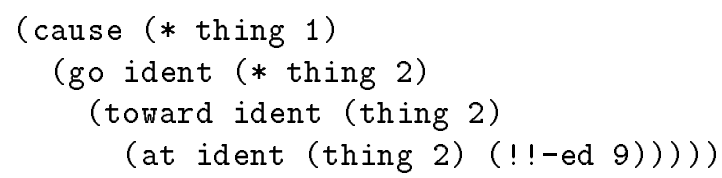

(7) I buffed the scuff marks off the floor.

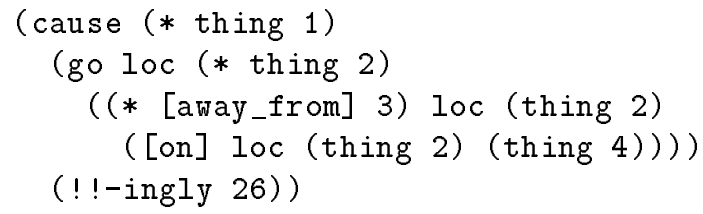

Scuff marks becomes the theme and off the floor a source PP, and the atelic verb in (6) becomes telic in (7). By their structure alone, it is not apparent that these LCSs should be related by lexical rules; and in fact, there are many classes that are plausibly represented by (6), but not necessarily lexically related to a class with an LCS like (7).

Many of the representations like (6) were changed to reflect (a)telicity (see Dorr and Olsen (1997)). This produces LCSs that appear even farther from there telic counterparts compositionally, thought of in terms (simple) transformations on the atelic form. Our new version of (6) is given here:

(8) I buffed the floor.

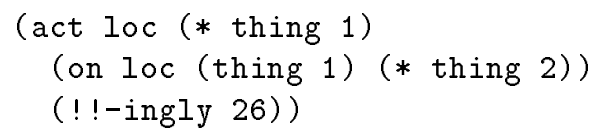


Next we describe how our (new) systematic link between LCSs and aspect was used to induce the desired compositional relation on the set of LCSs. This has the advantage of producing a (compact) lexicon that is systematically integrated with composition operations that are theoretically motivated.

\section{Aspectual Composition}

As mentioned above, our database was refined to allow lexical aspect (state vs. event, durative vs. punctiliar, and (a)telicity) to be inferred from LCSs (Dorr and Olsen, 1997). A version of the algorithm described there partitions the LCSs into subsets according to aspect, producing a partition of singly-marked LCSs (states), doubly-marked ones (activities or achievements) and fully marked ones (accomplishments). (Refer back to Table 1.) We then examine Levin's classes of verbs, to see if the alternations that apply to them received LCSs of differing aspect, with one set of aspectual features a proper subset of the other. If so, we take it to be the case that the subclass with the latter feature set is derived by a lexical rule from the subclass with the first feature set.

Aspect set inclusion within verb class induces a relation on this set of 237 LCSs that is defined by 109 pairs of LCSs: 71 aspectually basic subclasses are paired with one or more of 68 composed classes; at least 175 subclasses may be related by a lexical rule, but do not show a monotonic change in aspect. As refinement of the LCSs progresses, additional features will be mechanically read from, or introduced into, the LCSs, which will further partition the set, and increase the compositionality.

\section{$5 \quad$ Deriving Lexical Rules}

The relation mentioned above is many-to-many on the current set of LCSs-and a 1-to-many or many-to-1 relation is already problematic for the formulation of lexical rules, if lexical rules are be defined strictly in terms of conceptual structure. More than one state LCS expands compositionally to the following activity LCS, to which 24 of Levin's verb classes were assigned (in whole or in part):

(9) I carried it (for an hour).

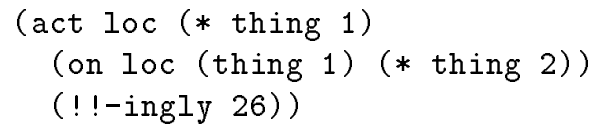

This in turn expands into several different accomplishment LCSs, depending on the verb class. Consider the following (for Slide and Carry Verbs, (Classes 11.2 and 11.4): 
(10) I carried/slid her a beer.

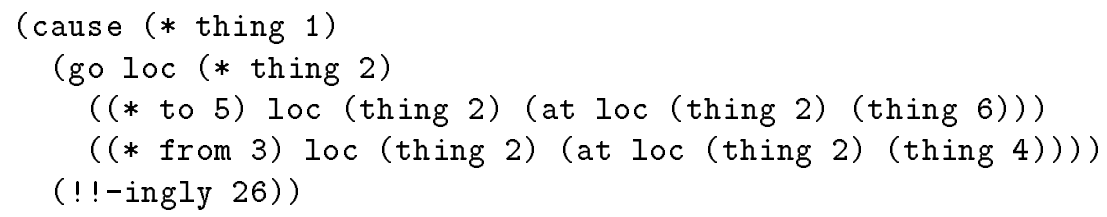

This corresponds as well to syntactic/semantic frames such as I sent/brought/drove her a beer (11.1,11.3 and 11.5, respectively) and The gentleman bussed/drove/danced/ran the kids to school (Classes 51.4.1, 51.4.2, 51.3.2, 51.5, 51.4.2). These do not all decompose into the same LCS, because they do not all participate in the same atelic frame. Consider: He carried/?sent/?brought the package for an hour.

Thus, it is one thing to design LCSs that closely reflect class semantics, and another thing to provide a systematic account of verb behavior via the LCSs, in which there is a clear relationship between some aspect of the conceptual structure and the use or non-use of a corresponding verb in some alternation. Table 2 lists the basic LCSs in use in an abbreviated form, and connections found via our aspectual analysis. The first column lists the current number of such connections; the second column lists the number connections from a basic LCS that do not show a change in aspect. ${ }^{3}$ This should be taken as rough indication of the plausible basic LCSs and connections that are easily read from Levin's classification.

We note that a handful of the primitive-field combinations are "undershifted." Of the 78 total number of possible primitive-field combinations, 29 occur in the database - the ones marked with "Y" in Table 3, and of these, six basic forms (BE Circ, GO Circ, GO Exist, GO_EXT Loc, STAY Circ, and STAY Exist) do not shift into non-basic structures. For example, Avoid Verbs (avoid, dodge, duck, elude, evade, shun, sidestep) do not shift into the causative counterpart STAY Circ. Examination of why these do not shift, whether due to omissions in Levin or impossible lexical rules, will be conducted in future research.

In addition to this observation, it is clear from the results above that shared LCSs points to needed refinements in Levin's verb classification. This may be the case for the group of Class 51 verbs above-verbs that name only a manner of motion, which Levin put into different classes for mostly non-syntactic reasons. This, then would be a case where the distinguishing features Levin gives are actually more inert linguistically, and not part of the semantic 'structure', the

\footnotetext{
${ }^{3}$ There are also 129 subclasses that were assigned just one LCS (and do not share verbs with any other subclass). These include classes of verbs that appear with a range of prepositions, but otherwise don't show much syntactic variation (such as the Class 9 Verbs of Putting: put it in/under there, on/under/near the chair, etc) and some that have an LCS with an optional substructure, usually corresponding to a prepositional phrase; these are also aspectually unvarying.
} 


\begin{tabular}{|c|c|c|c|c|}
\hline $\begin{array}{c}\text { Number of } \\
\text { Current } \\
\text { Connections }\end{array}$ & $\begin{array}{l}\text { Number of } \\
\text { Remaining } \\
\text { Connections }\end{array}$ & $\begin{array}{c}\text { Basic } \\
\text { LCS }\end{array}$ & & $\begin{array}{c}\text { Non-Basic } \\
\text { LCS }\end{array}$ \\
\hline 19 & 32 & $(\operatorname{act} 10 \mathrm{c})$ & $\rightarrow$ & (cause go ident) \\
\hline 29 & & & $\rightarrow$ & (cause go $10 \mathrm{c}$ ) \\
\hline 3 & & & $\rightarrow$ & (cause go perc) \\
\hline 5 & 15 & (act perc) & $\rightarrow$ & (cause go perc) \\
\hline 5 & & (be exist) & $\rightarrow$ & (act $10 \mathrm{c})$ \\
\hline 1 & & & $\rightarrow$ & (cause go ident) \\
\hline 10 & 3 & (be ident) & $\rightarrow$ & (act $10 \mathrm{c})$ \\
\hline 7 & & & $\rightarrow$ & (cause be ident) \\
\hline 5 & & & $\rightarrow$ & (cause go ident) \\
\hline 2 & & & $\rightarrow$ & (cause go perc) \\
\hline 1 & & & $\rightarrow$ & (let be ident) \\
\hline 4 & 5 & (be $10 \mathrm{c}$ ) & $\rightarrow$ & (act 10c) \\
\hline 4 & 19 & (be perc) & $\rightarrow$ & (act perc) \\
\hline 1 & & (be $\overline{\text { poss }}$ ) & $\rightarrow$ & (cause be $10 c$ ) \\
\hline 2 & 3 & (go ident) & $\rightarrow$ & (cause go ident) \\
\hline 1 & & & $\rightarrow$ & (cause go perc) \\
\hline 1 & 11 & (go loc) & $\rightarrow$ & (cause go ident) \\
\hline 2 & & & $\rightarrow$ & (cause go loc) \\
\hline 6 & 11 & (go perc) & $\rightarrow$ & (cause go perc) \\
\hline 1 & 1 & $($ stay loc) & $\rightarrow$ & (cause stay loc) \\
\hline
\end{tabular}

Table 2: A Set of (Abbreviated) LCSs for Levin's Verb Classes 


\begin{tabular}{|l|l|l|l|l|l|l|}
\hline \multirow{2}{*}{ Primitive } & \multicolumn{6}{|c|}{ Field } \\
\cline { 2 - 7 } & Circ & Exist & Ident & Loc & Perc & Poss \\
\hline ACT & N & N & N & Y & Y & N \\
\hline BE & Y & N & Y & Y & Y & Y \\
\hline GO & Y & Y & Y & Y & Y & N \\
\hline GO_EXT & N & N & N & Y & N & N \\
\hline STAY & Y & Y & N & Y & N & N \\
\hline CAUSE BE & Y & N & Y & Y & N & N \\
\hline CAUSE GO & N & Y & Y & Y & Y & Y \\
\hline CAUSE GO_EXT & N & N & N & N & N & N \\
\hline CAUSE STAY & N & N & Y & Y & Y & N \\
\hline LET BE & N & N & Y & N & N & N \\
\hline LET GO & N & N & N & N & N & Y \\
\hline LET GO_EXT & N & N & N & N & N & N \\
\hline LET STAY & N & N & N & N & N & N \\
\hline
\end{tabular}

Table 3: 29 Primitive-Field combinations in LCS Database

LCS in this case (Grimshaw, 1993; Pinker, 1989; Levin and Rappaport Hovav, To appear). Further examination will determine which of the classes named by Levin were, in fact, semantically based in the relevant way. We are currently investigating a number of possible inert features that appear to influence aspectual shifts: (1) lexical blocking - cases where another lexical item is available to accommodate the aspectual shift, e.g., be vs. become; (2) syntactic variations, e.g., exist vs. existing; (3) lexical-semantic classes, e.g, nonmotion activities are less likely to become accomplishments; and (4) cross-linguistic variationFrench activities are less likely to become accomplishments.

\section{Conclusions}

Aspectual information has proven to be useful in contributing to the IL development in at least two areas. From the linguistic standpoint, it allows a refinement of the aspect model in Olsen $(1994 ; 1997)$ which provided necessary but not sufficient conditions for aspectual composition. It already permits a systematic refinement of the verb classifications in Levin (1993), and contributes to a systematic specification of the meaning components (via LCSs and their composition, or via verb classes and their theoretical composition), which ultimately determine that classification. From the computational perspective, this approach will reduce the lexicon (to the most aspectually simple LCSs, currently) and at the same time, more properly constrain its compositional possibilities. 
Other elements of distribution and semantics are operative in determining that meanings are related by lexical rule (Levin and Rappaport Hovav, 1995); future work will integrate these into our system. Levin's work does not include an explicit relation between aspect and verb behavior, though as it turns out, it parallels a large part of the verb behavior catalogued there. Our next step is to expand our investigation to the particular alternations that don't typically reflect a change in aspect, such as those involving instruments (John cut the cake (with a knife)) or causativization (John broke the lamp/The lamp broke).

Additional areas of future investigation include an analysis of verbs in less apparently related classes (including verbs of change of state such as Marry and Orphan verbs.); or the Cut verbs (21.1/2) and Poke verbs (19); Carve verbs (21.2) and Cook verbs (45.3). Clearly a careful comparison is necessary, facilitated by the compositional structure described here.

\section{Acknowledgements}

The work was supported, in part, by National Science Foundation Presiden-

tial Faculty Fellowship (PFF/PECASE) Award IRI-9629108, Department of Defense contract MDA90496C1250, DARPA/ITO Contract N66001-97-C-8540, Army Research Laboratory contract LETTER11097 through United Research Corporation, and Army Research Laboratory contract DAAL03-91-C-0034 through Battelle.

\section{References}

Bresnan, Joan, editor. 1982. The Mental Representation of Grammatical Relations. The MIT Press, Cambridge, MA.

Dorr, Bonnie J. 1997. Large-Scale Acquisition of LCS-Based Lexicons for Foreign Language Tutoring. In Proceedings of the ACL Fifth Conference on Applied Natural Language Processing (ANLP), pages 139-146, Washington, $\mathrm{DC}$.

Dorr, Bonnie J. To appear. Large-Scale Dictionary Construction for Foreign Language Tutoring and Interlingual Machine Translation. Machine Translation, 12(1).

Dorr, Bonnie J., James Hendler, Scott Blanksteen, and Barrie Migdalof. 1993. Use of Lexical Conceptual Structure for Intelligent Tutoring. Technical Report UMIACS TR 93-108, CS TR 3161, University of Maryland.

Dorr, Bonnie J., Jim Hendler, Scott Blanksteen, and Barrie Migdalof. 1995. Use of LCS and Discourse for Intelligent Tutoring: On Beyond Syntax. In Melissa Holland, Jonathan Kaplan, and Michelle Sams, editors, Intelligent 
Language Tutors: Balancing Theory and Technology. Lawrence Erlbaum Associates, Hillsdale, NJ, pages 289-309.

Dorr, Bonnie J. and Mari Broman Olsen. 1997. Deriving Verbal and Compositional Lexical Aspect for NLP Applications. In Proceedings of the 35th Annual Meeting of the Association for Computational Linguistics (ACL-97), pages 151-158, Madrid, Spain, July 7-12.

Dowty, David. 1979. Word Meaning in Montague Grammar. Reidel, Dordrecht.

Grimshaw, Jane. 1993. Semantic Structure and Semantic Content in Lexical Representation. unpublished ms., Rutgers University, New Brunswick, NJ.

Guerssel, Mohamed, Kenneth Hale, Mary Laughren, Beth Levin, and Josie White Eagle. 1985. A Cross-linguistic Study of Transitivity Alternations. In W. H. Eilfort, P. D. Kroeber, and K. L. Peterson, editors, Papers from the Parasession on Causatives and Agentivity at the Twenty-First Regional Meeting, CLS 21, Part 2. The Chicago Linguistic Society, Chicago, IL, April, pages 48-63.

Jackendoff, Ray. 1983. Semantics and Cognition. The MIT Press, Cambridge, MA.

Jackendoff, Ray. 1990. Semantic Structures. The MIT Press, Cambridge, MA.

Levin, Beth. 1993. English Verb Classes and Alternations: A Preliminary Investigation. University of Chicago Press, Chicago, IL.

Levin, Beth and Malka Rappaport Hovav. 1995. Unaccusativity: At the SyntaxLexical Semantics Interface. The MIT Press, Cambridge, MA. LI Monograph 26.

Levin, Beth and Malka Rappaport Hovav. To appear. Building Verb Meanings. In M. Butt and W. Gauder, editors, The Projection of Arguments: Lexical and Syntactic Constraints. CSLI.

Moens, Marc and Mark Steedman. 1988. Temporal Ontology and Temporal Reference. Computational Linguistics: Special Issue on Tense and Aspect, $14(2): 15-28$.

Nirenburg, Sergei, Jaime Carbonell, Masaru Tomita, and Kenneth Goodman, editors. 1992. Machine Translation: A Knowledge-Based Approach. Morgan Kaufmann Publishers, San Mateo, CA.

Olsen, Mari Broman. 1994. The Semantics and Pragmatics of Lexical and Grammatical Aspect. Ph.D. thesis, Northwestern University, Evanston, IL.

Olsen, Mari Broman. 1997. A Semantic and Pragmatic Model of Lexical and Grammatical Aspect. Garland, New York. 
Pinker, Steven. 1984. Language Learnability and Language Development. MIT Press, Cambridge, MA.

Pinker, Steven. 1989. Learnability and Cognition: The Acquisition of Argument Structure. The MIT Press, Cambridge, MA.

Pustejovsky, James. 1991. The Syntax of Event Structure. In Beth Levin and Steven Pinker, editor, Lexical and Conceptual Semantics. Blackwell, Cambridge, MA, pages $47-81$.

Sams, Michelle. 1993. An Intelligent Foreign Language Tutor Incorporating Natural Language Processing. In Proceedings of Conference on Intelligent Computer-Aided Training and Virtual Environment Technology, NASA: Houston, TX.

Smith, Carlota. 1991. The Parameter of Aspect. Kluwer, Dordrecht.

Verkuyl, Henk. 1972. On the Compositional Nature of the Aspects. Foundations of Language Supplementary Series 15. Reidel, Dordrecht.

Verkuyl, Henk. 1993. A Theory of Aspectuality: The Interaction Between Temporal and Atemporal Structure. Cambridge University Press, Cambridge and New York.

Weinberg, Amy, Joseph Garman, Jeffery Martin, and Paola Merlo. 1995. Principle-Based Parser for Foreign Language Training in German and Arabic. In Melissa Holland, Jonathan Kaplan, and Michelle Sams, editors, Intelligent Language Tutors: Theory Shaping Technology. Lawrence Erlbaum Associates, Hillsdale, N.J, pages 23-44. 